\title{
Functional Specialization of the Axon Initial Segment by Isoform-Specific Sodium Channel Targeting
}

\author{
Tatiana Boiko, ${ }^{1 \star}$ Audra Van Wart, ${ }^{1 *}$ John H. Caldwell, ${ }^{3}$ S. Rock Levinson, ${ }^{4}$ James S. Trimmer, ${ }^{2}$ and Gary Matthews ${ }^{1}$ \\ Departments of ${ }^{1}$ Neurobiology and Behavior and ${ }^{2}$ Biochemistry and Cell Biology, State University of New York, Stony Brook, New York 11794, and \\ Departments of ${ }^{3}$ Cellular and Structural Biology and ${ }^{4}$ Physiology, University of Colorado Medical School, Denver, Colorado 80262
}

\begin{abstract}
Voltage-dependent sodium channels cluster at high density at axon initial segments, where propagating action potentials are thought to arise, and at nodes of Ranvier. Here, we show that the sodium channel $\mathrm{Na}_{\mathrm{v}} 1.6$ is precisely localized at initial segments of retinal ganglion cells (RGCs), whereas a different isoform, $\mathrm{Na}_{\mathrm{v}} 1.2$, is found in the neighboring unmyelinated axon. During development, initial segments first expressed $\mathrm{Na}_{\mathrm{v}} 1.2$, and $\mathrm{Na}_{\mathrm{v}} 1.6$ appeared later, approximately in parallel with the onset of repetitive RGC firing. In Shiverer mice, $\mathrm{Na}_{\mathrm{v}} 1.6$ localization at the initial segment was unaffected, although $\mathrm{Na}_{\mathrm{v}} 1.6$ expression was severely disrupted in the aberrantly myelinated optic nerve. Targeting or retention of $\mathrm{Na}_{\mathrm{v}} 1.6$ requires molecular interactions that normally occur only at initial segments and nodes of Ranvier. Expression at nodes but not initial segments exhibits an additional requirement for intact myelination. Because of their high density at the initial segment, $\mathrm{Na}_{\mathrm{v}} 1.6$ channels may be crucial in determining neuronal firing properties.
\end{abstract}

Key words: sodium channels; initial segment; action potential initiation; retina; retinal ganglion cell; development; optic nerve

\section{Introduction}

Although voltage-gated sodium channels are expressed rather uniformly along unmyelinated axons (Westenbroek et al., 1989), they accumulate at high density at the axon initial segment (Catterall, 1981; Wollner and Catterall, 1986). This increased density is thought to lower the threshold for initiation of action potentials and, hence, to determine axonal firing frequency (Coombs et al., 1957; Palay et al., 1968; Carras et al., 1992). In myelinated axons, sodium channels also cluster at high density at nodes of Ranvier (for review, see Peles and Salzer, 2000). Sodium-channel clustering at both initial segments and nodes of Ranvier is governed by complex, largely unknown mechanisms (for review, see Bennett and Baines, 2001). These mechanisms include the association of channel clusters with coexpressed ankyrin-G (Kordeli et al., 1995; Zhou et al., 1998) and BIV-spectrin (Berghs et al., 2000), which may link channels to the cytoskeleton, and with the neuronal cell-adhesion molecules neurofascin 186 and NrCAM (Davis et al., 1996; Lambert et al., 1997), which may provide extracellular interactions.

The high density of sodium channels and partner proteins at initial segments and nodes of Ranvier suggests that these two axonal compartments have similar molecular organization and may share mechanisms for sodium-channel clustering. Indeed, the initial segment might be regarded as the "first node" in many myelinated axons. However, in retinal ganglion cells (RGCs) of most mammals, the axons remain unmyelinated for millimeters within the retina and become myelinated only after they enter the

\footnotetext{
Received 0ct. 8, 2002; revised Dec. 26, 2002; accepted Dec. 30, 2002.

This work was supported by National Institutes of Health Grants EY03821 (G.M.), NS26505 (J.H.C.), NS34375 (S.R.L.), and NS34383 (J.S.T.). We thank Dr. Matthew N. Rasband for useful discussions and Dr. Gail Mandel for access to her confocal microscope.

T.B. and A.V.W. contributed equally to this work.

Correspondence should be addressed to Dr. Gary G. Matthews, Department of Neurobiology and Behavior, Life Sciences 550, State University of New York, Stony Brook, NY 11794-5230. E-mail: Gary.G.Matthews@sunysb.edu. Copyright $\odot 2003$ Society for Neuroscience $\quad 0270-6474 / 03 / 232306-08 \$ 15.00 / 0$
}

optic nerve and pass through the lamina cribrosa. Therefore, RGC axons consist of distinct myelinated and unmyelinated zones. In this situation, the initial segment is spatially separated from the first occurrence of myelinating oligodendrocytes and thus forms a clearly distinguishable subdivision of the unmyelinated axon rather than a first node.

We have shown previously that distinct sodium-channel subtypes are targeted to the unmyelinated and myelinated regions of RGC axons, with $\mathrm{Na}_{\mathrm{v}} 1.2$ found uniformly throughout the unmyelinated region, whereas $\mathrm{Na}_{\mathrm{v}} 1.6$ clustered at nodes of Ranvier in the myelinated optic nerve (Boiko et al., 2001). Therefore, the question arises whether the sodium channels that cluster at high density at the initial segments of ganglion-cell axons are the $\mathrm{Na}_{\mathrm{v}} 1.2$ channels found in the surrounding unmyelinated region or the $\mathrm{Na}_{\mathrm{v}} 1.6$ channels that cluster at the distant nodes of Ranvier. Because RGCs serve to translate graded visual signals into a frequency code of action potentials, information about the particular sodium-channel subtype expressed at their initial segments is important in understanding how the retina encodes the visual world. In addition, we reported previously that the sodiumchannel isoform expressed at nodes of Ranvier changes with maturation in a manner that depends on the formation of compact myelin (Boiko et al., 2001). Therefore, the question also arises whether the isoform present at initial segments is similarly developmentally regulated. To approach these questions, we used isoform-specific antibodies to examine sodium-channel expression at RGC initial segments during normal development and in mutant mice that fail to form compact myelin.

\section{Materials and Methods}

Tissue preparation. Animal use followed guidelines established by the National Institutes of Health and the Institutional Animal Care and Use Committee. Sprague Dawley rats older than postnatal day 14 (P14) were killed using $\mathrm{CO}_{2}$, and $\mathrm{P} 2-\mathrm{P} 14$ animals were killed by rapid decapitation. Immediately after death, eyes were dissected out and immersion-fixed for 1.5-2 hr on ice in freshly prepared 4\% paraformaldehyde. For flat- 

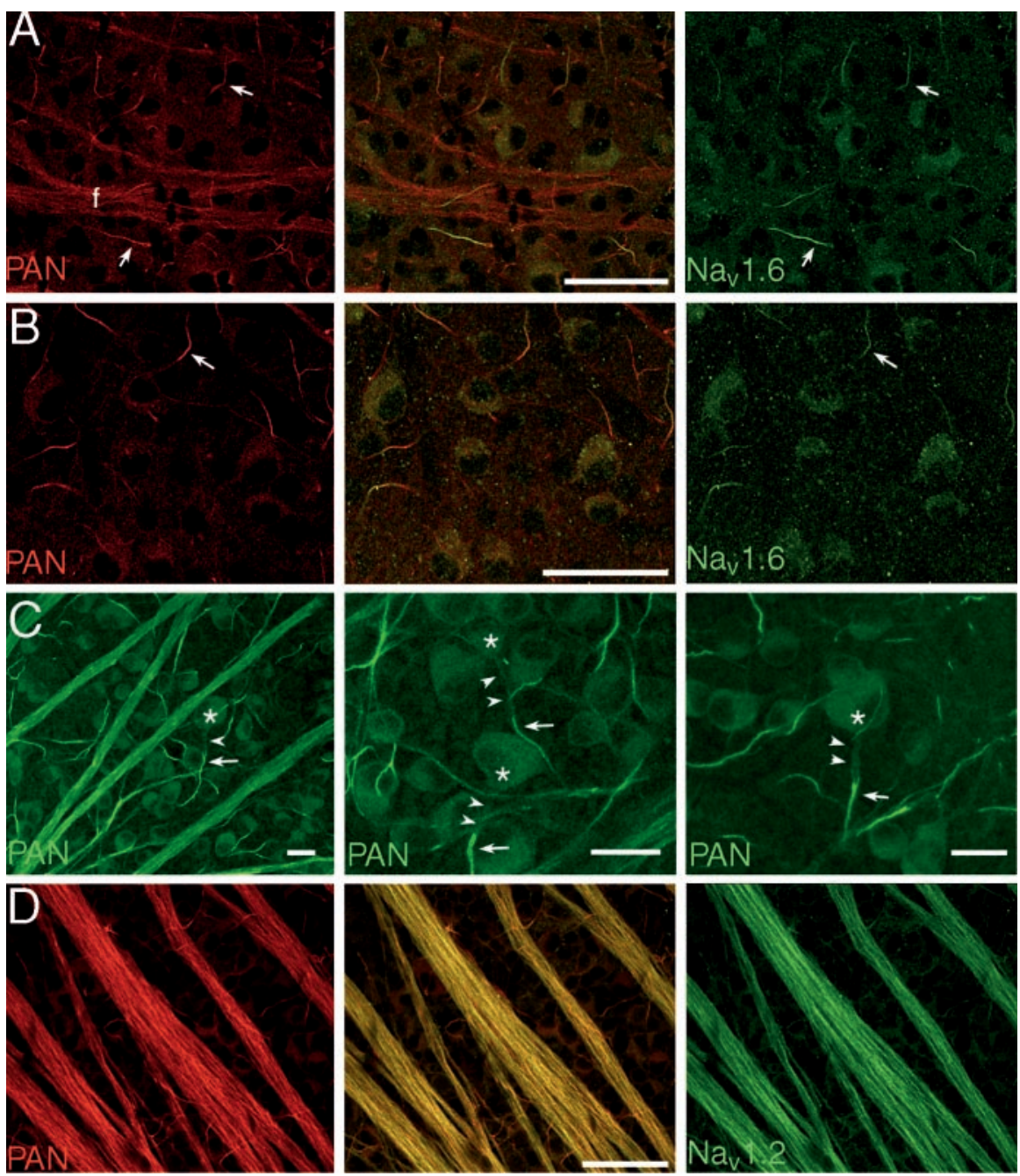

Figure 1. $\mathrm{Na}_{\mathrm{v}} 1.2$ was found throughout the unmyelinated zone of adult $\mathrm{RGC}$ axons, whereas $\mathrm{Na}_{\mathrm{v}} 1.6$ was localized specifically to axonal initial segments. A, Double-labeling of rat retina with PAN (red) and anti-Na 1.6 (green) revealed no colocalization in fascicles of unmyelinated $\mathrm{RGC}$ axons $(f)$. $\mathrm{Na}_{\mathrm{v}} 1.6$ immunoreactivity was selectively observed in $\mathrm{RGC}$ somata and in short segments of axons, representing the distal portion of putative initial segments (arrows indicate 2 examples). B, An image taken from a region of the peripheral retina that is devoid of axon fascicles. Bright PAN-stained processes (red) coincide with $\mathrm{Na}_{\mathrm{v}} 1.6$ immunoreactivity ( green). The arrows indicate a bright segment of PAN staining seemingly connected by a more dimly stained process to an adjacent RGC soma. C, Examples of PAN-stained RGCS, illustrating the relationship of the brightly stained axonal segment to the cell body. Arrows indicate the start of the brightly stained segment, asterisks indicate the cell body, and arrowheads indicate the more dimly stained proximal portion of the axon. In these examples, the distance from the soma to the brightly stained segment was $\sim 15-20$ $\mu \mathrm{m}$. D, Double-labeling with PAN (red) and anti- $\mathrm{Na}_{v} 1.2$ (green) reveals $\mathrm{Na}_{\mathrm{v}} 1.2$ immunoreactivity throughout $\mathrm{RGC}$ axons. This image was taken from an intermediate zone of the retina with a higher density of axon fascicles. Scale bars: $A, B, D, 50 \mu \mathrm{m} ; C, 20$ $\mu \mathrm{m}$. All images were obtained from flat mounts of intact retinas. Images in $A, B$, and $D$ are projections of two consecutive optical sections, whereas images in Care projections of a series of optical sections spanning 6 $6 \mu \mathrm{m}$ from near the vitreal surface to the RGC layer.

mount preparation (Voigt and Wässle, 1987), retinas were processed free-floating. For sections, retinas were hemisected, cryoprotected overnight at $4^{\circ} \mathrm{C}$ in $20 \%$ sucrose, frozen in M1 medium (Shandon Lipshaw, Pittsburgh, PA), and cryosectioned at $30 \mu \mathrm{m}$ in a plane that was perpendicular to the surface of the retina.

Immunohistochemistry reagents. Flat mounts and cryosections were processed for immunohistochemistry with antibodies characterized previously. Pan-specific polyclonal (Dugandzija-Novakovic et al., 1995) and monoclonal (K58/35) (Rasband et al., 1999) antibodies were generated against a conserved sequence present in all vertebrate $\mathrm{Na}_{\mathrm{v}} 1$ isoforms. Anti-peptide rabbit polyclonal antibodies against the $\mathrm{Na}_{\mathrm{v}} 1.2$ isoform were developed against a unique sequence in the $\mathrm{Na}_{\mathrm{v}} 1.2 \mathrm{C}$ terminus (Gong et al., 1999). Anti-peptide rabbit polyclonal antibodies against $\mathrm{Na}_{\mathrm{v}} 1.6$ were generated against a synthetic peptide Laboratories). corresponding to a unique sequence in the large intracellular domain I-II loop of $\mathrm{Na}_{\mathrm{v}} 1.6$ (Krzemien et al., 2000). Mouse monoclonal anti- $\mathrm{Na}_{\mathrm{v}} 1.6(\mathrm{~K} 87 \mathrm{~A} / 10)$ was raised against this same peptide. Monoclonal anti-neurofascin antibody was generated against a neurofascin-glutathione $S$-transferase fusion protein and detects both neurofascin 155 and neurofascin 186 (M. N. Rasband and J. S. Trimmer, personal communication). Mouse monoclonal ankyrin-G antibody (clone 4G3F8) was purchased from Santa Cruz Biotechnology (Santa Cruz, CA). Alexa 488-conjugated secondary antibodies (Molecular Probes, Eugene, OR) were used to detect rabbit polyclonal antibodies, and Cy-3-conjugated (Jackson ImmunoResearch, West Grove, PA) or Alexa 568-conjugated (Molecular Probes) secondary antibodies were used for visualization of the mouse monoclonal antibodies.

Immunostaining of cryosections. Slides with cryosections were thawed at room temperature (RT), washed three times for $10 \mathrm{~min}$ in PBS, and then incubated for $2 \mathrm{hr}$ at RT with a blocking solution consisting of $6 \%$ NGS in PBS plus $0.3 \%$ Triton X-100 (PBST). Primary antibodies were diluted in blocking solution, spun down for $10 \mathrm{~min}$ at $14,000 \mathrm{rpm}$ in a microcentrifuge at $4^{\circ} \mathrm{C}$, and applied to sections to be incubated overnight at RT in sealed humidified chambers. Slides were then washed three times for 10 min in PBS in glass slide containers while shaking. After the washes, the secondary antibodies, which were diluted in blocking mix and spun down at 14,000 rpm for $10 \mathrm{~min}$, were applied for $45 \mathrm{~min}$ at RT in the dark. After washing one time for $10 \mathrm{~min}$ in PBST and two times for $10 \mathrm{~min}$ in PBS, sections were dried for 10 min and mounted in Vectashield (Vector Laboratories, Burlingame, CA). Blocking controls for nonspecific staining were performed on sections adjacent to experimental sections by preincubation of the primary antibodies with a large molar excess of the corresponding peptides (data not shown). In experiments using Shiverer mice (C3Heb/FeJ-MBPShi; The Jackson Laboratory, Bar Harbor, ME), sections from wild-type mice served as controls and were processed for immunohistochemistry on the same slides as the Shiverer sections.

Immunostaining of flat mounts. Staining was performed using a protocol similar to that used for the cryosections, with the following exceptions: Whole retinas were incubated freefloating in solutions inside sealed plastic containers ( $1.5 \mathrm{ml}$ centrifuge tubes or $2 \mathrm{ml}$ plastic autoanalyzer cups). Primary incubations were done at RT for $3 \mathrm{~d}$ on a nurator in the presence of $3 \mathrm{~mm}$ sodium azide and then washed three times for $10 \mathrm{~min}$ in PBS. Secondary incubations were done for $1 \mathrm{hr}$, followed by one wash for $15 \mathrm{~min}$ in PBST and two washes for $15 \mathrm{~min}$ in PBS. Several cuts were then made at the edges of the retina toward the optic disc, and after being dipped in deionized water to eliminate excess salt, retinas were spread flat and mounted, RGC side down, onto a coverslip that was covered with a slide bearing a drop of Vectashield (Vector

Confocal imaging. Images were acquired using a laser-scanning confocal microscope [LSM 510 (Zeiss, Thornwood, NY) or FV-300 (Olympus Optical, Tokyo, Japan)], initially processed using Zeiss LSM or Olympus Optical FluoView software, and later exported into Adobe Photoshop 7.0 
(Adobe Systems, San Jose, CA) for final processing. Images comparing peptide-blocked and -unblocked antibody labeling were acquired and digitally processed identically. No staining above background was detectable in sections incubated with a secondary antibody alone or with a primary antibody preincubated with a blocking peptide (data not shown). For imaging of retinal flat mounts, a series of confocal optical sections was taken, beginning at the surface of the retina and extending through the ganglion-cell layer into the inner plexiform layer. This procedure ensured that the entire course of ganglion-cell axons from somata to overlying axon fascicles would be contained within the stack of confocal sections. For cryosections, a series of confocal images was collected extending through the section thickness, bracketing cells and neurites of interest. Nominal confocal section thickness was $0.3 \mu \mathrm{m}$, and successive sections were separated by $0.5 \mu \mathrm{m}$. As indicated in the captions, figures show either planar projections of a series of successive confocal images or representative individual confocal sections.
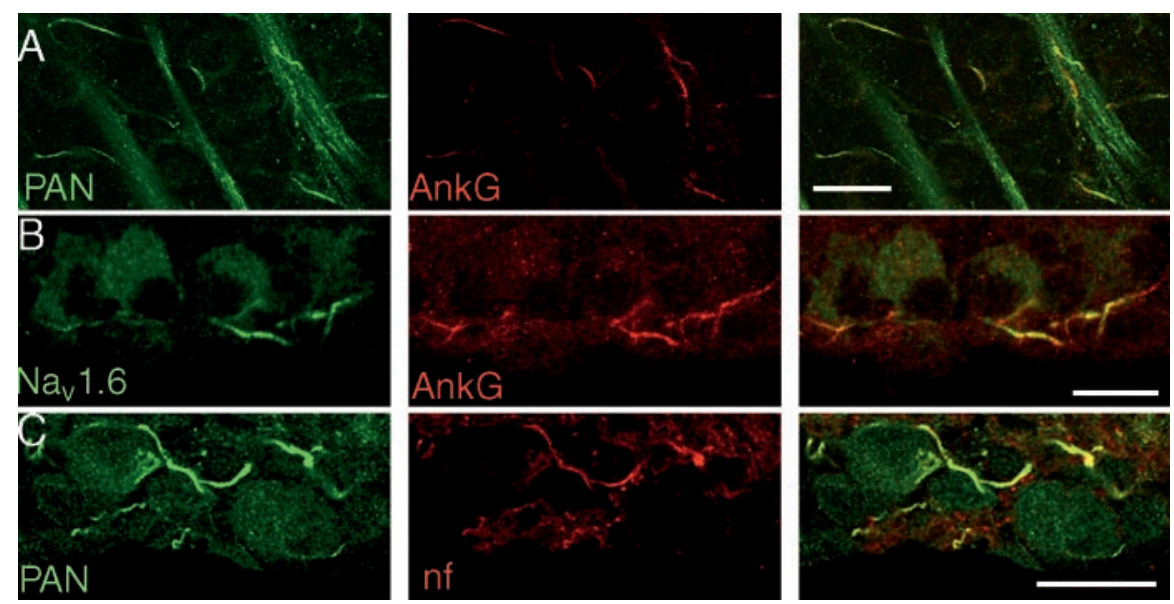

Figure 2. $\mathrm{Na}_{\mathrm{v}} 1.6$, ankyrin-G $(A n k G)$, and neurofascin $(n f)$ colocalize at initial segments of adult RGC axons. $A$, Flat mount of adult rat retina stained for PAN ( green) and ankyrin-G (red) shows clusters of ankyrin-G immunoreactivity colocalized with intense PAN-positive regions representing RGC initial segments. Little ankyrin-G immunofluorescence was observed in RGC axon bundles. $B$, Cryosections of rat retina revealed colocalization between $\mathrm{Na}_{\mathrm{v}} 1.6$ ( green) and ankyrin-G (red) at RGC initial segments. C, Brightly PAN-positive regions of RGC axons ( green) colocalized with neurofascin immunoreactivity (red) in cryosections, also confirming these regions as initial segments. Scale bar, $20 \mu \mathrm{m}$. Individual optical sections are shown in $A$ and $C$; the image in $B$ is a projection of sections spanning $1.5 \mu \mathrm{m}$.

\section{Results}

\section{$\mathrm{Na}_{\mathrm{v}} 1.6$ sodium channels cluster at initial segments of} ganglion-cell axons in the adult retina

Immunofluorescence staining with a monoclonal antibody (PAN) that recognizes all neuronal sodium-channel isoforms (Rasband et al., 1999) revealed uniform sodium-channel immunoreactivity throughout fascicles of unmyelinated RGC axons passing across the vitreal surface of the retina (Fig. $1 \mathrm{~A}$, left, $f$ indicates axon fascicle). Double staining of the same tissue with an antibody specific for $\mathrm{Na}_{\mathrm{v}} 1.6$ sodium channels (Caldwell et al., 2000) produced no detectable immunoreactivity in the unmyelinated axon fascicles (Fig. $1 \mathrm{~A}$, right), in agreement with our previous results (Boiko et al., 2001). In addition to staining in fascicles, bright PAN immunofluorescence was observed between fascicles in short portions of axons 15-30 $\mu \mathrm{m}$ long and located near RGC somata. Two examples of the several such instances visible in Figure $1 \mathrm{~A}$ (left) are indicated by arrows. Unlike the axons in fascicles, PAN immunofluorescence in these short axon segments coincided with $\mathrm{Na}_{\mathrm{v}} 1.6$ immunoreactivity (Fig. $1 \mathrm{~A}$, right and middle). Thus, the clusters of sodium channels at the short axon segments near the somata contain a molecularly distinct isoform not found in the fasicles of unmyelinated axons more distant from somata.

Figure $1 B$ shows images from the peripheral retina, in which the distance between axon fascicles is greater, allowing the brightly PAN/ $\mathrm{Na}_{\mathrm{v}} 1.6$-positive axon segments to be viewed in isolation. Examination of adjacent confocal planes confirmed that bright PAN staining was confined to the axonal region shown. Thus, the short axon segments represent subregions in which sodium channels, specifically $\mathrm{Na}_{\mathrm{v}} 1.6$ channels, cluster at higher density. Sodium channels are known to occur at high density at axon initial segments (Catterall, 1981; Wollner and Catterall, 1986), suggesting that the $\mathrm{Na}_{\mathrm{v}}$ 1.6-labeled region represents the initial segment.

Close inspection showed that brightly PAN-labeled segments (Fig. 1C, arrows) were not immediately adjacent to their apparent cell bodies of origin (Fig. 1C, asterisks) and instead appeared to be separated from the soma by a stretch of more dimly stained axon (Fig. 1C, arrowheads). Indeed, because of the high density of gan- glion cells and the distance of the brightly stained segment from the soma, it was typically not possible to unambiguously assign an individual bright segment to a particular RGC, making it difficult to specify with precision the average separation of the brightly stained segment from the soma. This localization of a high density of sodium channels at a site distal from the soma differs from that reported by Wollner and Catterall (1986), who described sodium-channel immunoreactivity extending throughout the initial segment and axon hillock of RGCs. The reason for the discrepancy is not yet clear (see Discussion, however).

Double labeling with PAN and $\mathrm{Na}_{\mathrm{v}} 1$.2-specific antibodies demonstrated that the uniform PAN-specific sodium-channel immunoreactivity in the fascicles of unmyelinated RGC axons coincided with $\mathrm{Na}_{\mathrm{v}} 1.2$ immunofluorescence (Fig. 1D). Therefore, as reported previously, $\mathrm{Na}_{\mathrm{v}} 1.2$ sodium channels are present in the unmyelinated RGC axons, whereas $\mathrm{Na}_{\mathrm{v}} 1.6$ channels are excluded from the unmyelinated axon, except for the distal portion of the putative initial segment.

To determine whether the clusters of $\mathrm{Na}_{\mathrm{v}} 1.6$ sodium channels and the regions of bright PAN staining in fact represent initial segments, we compared immunostaining for sodium channels and ankyrin-G, which is expressed at initial segments (Kordeli et al., 1995; Lambert et al., 1997; Jenkins and Bennett, 2001; Komada and Soriano, 2002). Figure $2 \mathrm{~A}$ shows that antiankyrin-G (Kordeli et al., 1995) selectively labeled the short brightly PAN-positive axonal segments between fascicles. Similarly, $\mathrm{Na}_{\mathrm{v}}$ 1.6-positive sites also coincided with clusters of ankyrin-G immunoreactivity (Fig. 2B). In 254 initial segments defined by ankyrin-G staining, 242 (95\%) were positive for $\mathrm{Na}_{\mathrm{v}}$ 1.6. Another marker for the initial segment is neurofascin 186 (Kordeli et al., 1995), and Figure 2C shows that neurofascin immunoreactivity also colocalized with the clusters of sodium channels near RGC somata. These results confirm that the short $\mathrm{Na}_{\mathrm{v}}$ 1.6-positive regions do indeed represent initial segments of RGC axons, as defined by selective protein expression. Therefore, we will refer to this region of the axon as the initial segment, while keeping in mind that sodium-channel clustering is actually restricted to the distal portion of the anatomically defined initial segment (Fig. 1C). 

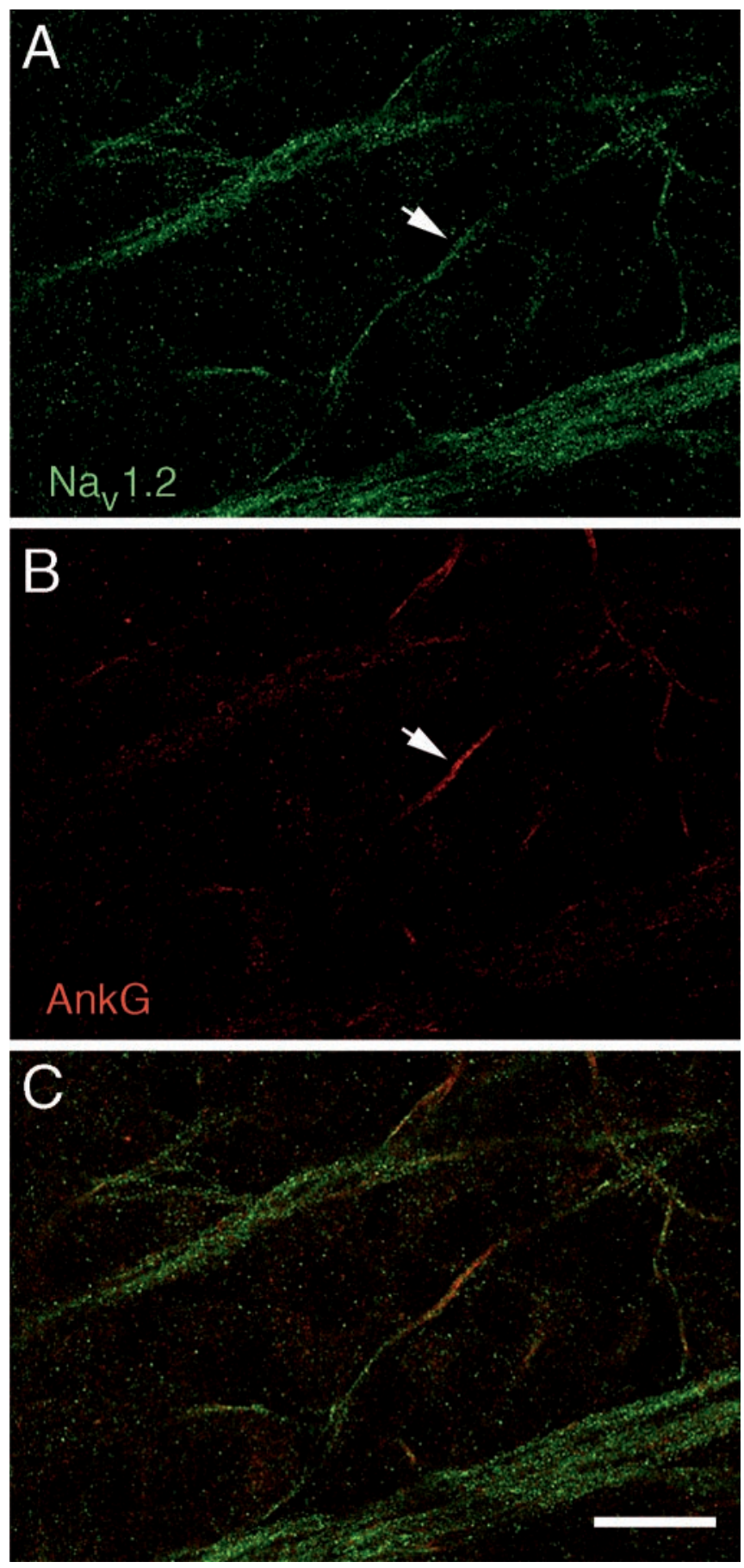

Figure 3. $\mathrm{Na}_{\mathrm{v}} 1.2$ immunoreactivity was detected throughout unmyelinated $\mathrm{RGC}$ axons, including the initial segment. $A, \mathrm{Na}_{\mathrm{v}} 1.2$ immunostaining in a flat mount of adult rat retina. $B$, Ankyrin-G immunostaining in the same field of view shown in $A$. C, Superposition of $\mathrm{Na}_{v} 1.2$ and Ankyrin-G immunofluorescence. Ankyrin-G immunoreactivity (red) was used to mark initial segments (arrow, B). Anti-Na 1.2 immunostaining ( green) was present in all parts of the RGC axon and colocalized with ankyrin-G in the initial segment (arrow, $A$ ). The cell body is not visible in this single optical section.

\section{$\mathrm{Na}_{\mathrm{v}} 1.2$ sodium channels are not excluded from initial segments}

The selectivity of $\mathrm{Na}_{\mathrm{v}} 1.6$ expression to the initial segment suggests that mechanisms exist to stabilize $\mathrm{Na}_{\mathrm{v}} 1.6$ at that location while excluding it from neighboring regions of the unmyelinated axon in which $\mathrm{Na}_{\mathrm{v}} 1.2$ is found. We next examined whether the
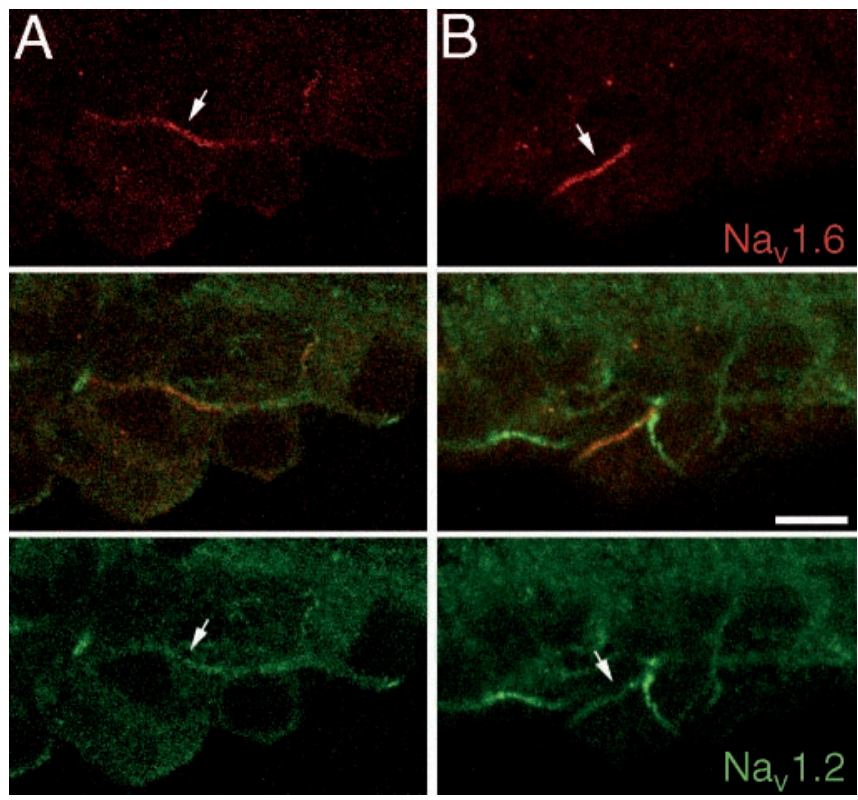

Figure 4. $\mathrm{Na}_{\mathrm{v}} 1.2$ immunofluorescence colocalized with $\mathrm{Na}_{\mathrm{v}} 1.6$ immunostaining at initial segments. Cryosections of P35 rat retina double-labeled with polyclonal anti-Na 1.2 (green) and monoclonal anti-Na 1.6 (red) further demonstrated the presence of $\mathrm{Na}_{\mathrm{v}} 1.2$ at initial segments. $A, \mathrm{Na}_{\mathrm{v}} 1.2$ staining was located in the $\mathrm{Na}_{\mathrm{v}} \mathrm{1}$.6-enriched initial segment (arrow) and in the flanking region of the $\mathrm{RGC}$ axon. B, Brightly $\mathrm{Na}_{\mathrm{v}} 1$.6-labeled initial segment (arrow) was also dimly stained with anti- $\mathrm{Na}_{v} 1.2$, which also stained axon regions without detectable $\mathrm{Na}_{v} 1.6$ immunoreactivity. Scale bar, $10 \mu \mathrm{m}$. Images show single confocal optical sections.

components necessary to restrict $\mathrm{Na}_{\mathrm{v}} 1.6$ to the initial segment exclude $\mathrm{Na}_{\mathrm{v}} 1.2$ or allow it to coexist with $\mathrm{Na}_{\mathrm{v}} 1.6$. In tissue double-labeled with anti- $\mathrm{Na}_{\mathrm{v}} 1.2$ and anti-ankyrin-G, initial segments were identified based on ankyrin-G staining. As illustrated in Figure 3, $\mathrm{Na}_{\mathrm{v}} 1.2$ immunoreactivity was present throughout the unmyelinated RGC axon, including the initial segment. In 100 ankyrin-G-positive initial segments, $92(92 \%)$ also showed detectable $\mathrm{Na}_{\mathrm{v}} 1.2$ staining, compared with $95 \%$ that showed detectable $\mathrm{Na}_{\mathrm{v}} 1.6$ staining (see above). Thus, $\mathrm{Na}_{\mathrm{v}} 1.2$ is not excluded from the initial segment, and the high density of sodium channels present at that location represents an amalgam of coexisting $\mathrm{Na}_{\mathrm{v}} 1.2$ and $\mathrm{Na}_{\mathrm{v}}$ 1.6. In this respect, the initial segment differs from the node of Ranvier in the myelinated optic nerve, in which $\mathrm{Na}_{\mathrm{v}} 1.2$ was undetectable at $>80 \%$ of adult nodes (Boiko et al., 2001).

To test directly for coexpression of $\mathrm{Na}_{\mathrm{v}} 1.6$ and $\mathrm{Na}_{\mathrm{v}} 1.2$ channels at RGC initial segments, sections were double-labeled with anti- $\mathrm{Na}_{\mathrm{v}} 1.2$ and anti- $\mathrm{Na}_{\mathrm{v}} 1.6$ antibodies. $\mathrm{Na}_{\mathrm{v}} 1.6$ immunoreactivity served to mark initial segments, based on the results presented in the previous section. Figure 4 demonstrates that axonal regions that exhibited $\mathrm{Na}_{\mathrm{v}} 1.6$ staining were also positive for $\mathrm{Na}_{\mathrm{v}} 1.2$, which directly confirms that $\mathrm{Na}_{\mathrm{v}} 1.2$ and $\mathrm{Na}_{\mathrm{v}} 1.6 \alpha$ subunits coexist at the initial segment. However, $\mathrm{Na}_{\mathrm{v}} 1.6$ was restricted exclusively to the initial segment, whereas $\mathrm{Na}_{\mathrm{v}} 1.2$ immunoreactivity was present both in the initial segment and in the distal portions of the unmyelinated RGC axon.

\section{$\mathrm{Na}_{\mathrm{v}} 1.2$ accounts for sodium-channel clusters at developing initial segments}

During development, $\mathrm{Na}_{\mathrm{v}} 1.2$ channels initially cluster at developing nodes and are replaced by the $\mathrm{Na}_{\mathrm{v}} 1.6$ subtype as the nodes mature (Boiko et al., 2001). Like nodes, adult initial segments express $\mathrm{Na}_{\mathrm{v}} 1.6$ sodium channels, as demonstrated above. There- 
fore, we next asked whether a similar developmental progression of $\mathrm{Na}_{\mathrm{v}} 1.6$ expression also occurs at the initial segment. We examined sodium-channel expression in RGC axons within the retina early in postnatal development, starting at P2. At all stages, ankyrin- $G$ immunoreactivity was used to mark initial segments. In the $\mathrm{P} 2$ rodent retina, ganglion cells are smaller and more numerous than in the adult (Perry et al., 1983; Maslim et al., 1986), and there are approximately twice as many optic nerve axons (Crespo et al., 1985). This results in numerous ankyrinG-positive initial segments, as seen in Figure 5. However, no $\mathrm{Na}_{\mathrm{v}} 1.6$ immunoreactivity was observed anywhere in the retina at P2 (Fig. 5). At P5, $\mathrm{Na}_{\mathrm{v}} 1.6$ immunostaining remained undetectable in the retina, and the first instances of fragmented $\mathrm{Na}_{\mathrm{v}} 1.6$ immunofluorescence were seen at P7 (data not shown). By P9, well defined $\mathrm{Na}_{\mathrm{v}} 1.6$ immunofluorescence was observed at a subset of ankyrin-G-positive initial segments (Fig. 5); in retinas of P14 rats, $\mathrm{Na}_{\mathrm{v}} 1.6$ expression at the initial segment neared the adult pattern (Fig. 5). This developmental trend is quantified in Table 1.

Even before birth, retinal ganglion cells generate propagating action potentials that play a role in establishing proper synaptic arrangements (Wong, 1999). Therefore, some other sodium-channel subtype would be expected to take the place of the absent $\mathrm{Na}_{\mathrm{v}} 1.6$ channels in initial segments at early developmental stages. As shown in Figure 6, $\mathrm{Na}_{\mathrm{v}} 1.2$ channels could perform this role. From $\mathrm{P} 2$ through adulthood, $\mathrm{Na}_{\mathrm{v}} 1.2 \mathrm{immu}-$ nofluorescence staining was present at ankyrin-G-positive initial segments, as well as in fascicles of unmyelinated axons. Table 1 summarizes the high percentage of $\mathrm{Na}_{\mathrm{v}} 1.2$-positive initial segments at all ages for comparison with the developmental pattern of increasing $\mathrm{Na}_{\mathrm{v}} 1.6$ expression. Thus, as with nodes of Ranvier in the myelinating optic nerve (Boiko et al., 2001), $\mathrm{Na}_{\mathrm{v}} 1.2$ channels cluster first at early initial segments, and $\mathrm{Na}_{\mathrm{v}} 1.6$ appears with maturation. However, unlike nodes, $\mathrm{Na}_{\mathrm{v}} 1.2$ expression does not disappear from initial segments as $\mathrm{Na}_{\mathrm{v}} 1.6$ expression rises.

\section{Hypomyelination in Shiverer mice does not affect the expression of $\mathrm{Na}_{\mathrm{v}} 1.6$ at the RGC initial segment}

$\mathrm{Na}_{\mathrm{v}} 1.6$ expression is severely reduced while $\mathrm{Na}_{\mathrm{v}} 1.2$ expression is enhanced in the myelinated optic nerve of Shiverer mice (Boiko et al., 2001), which fail to form compact myelin. This finding raises the possibility that $\mathrm{Na}_{\mathrm{v}} 1.6$ expression might also be disrupted at the initial segment in Shiverer RGCs. However, Figure $7 A$ shows strong $\mathrm{Na}_{\mathrm{v}} 1.6$ staining at the initial segments of RGCs in adult Shiverer retina. The pattern of $\mathrm{Na}_{\mathrm{v}} 1.6$ immunofluorescence in the retina of adult Shiverer mice was indistinguishable from that in wild-type mice (data not shown) or in rat retina (Fig. 1). That is, clusters of $\mathrm{Na}_{\mathrm{v}} 1.6$ immunoreactivity colocalized with intense PAN-labeled regions near ganglion-cell somata (Fig. 7A, left) and with ankyrin-G-positive initial segments (Fig. 7A, right). These data demonstrate that expression of sodium channels at the initial segment is apparently normal in adult Shiverer mice.

During development, early RGC initial segments in Shiverer retina were positive for $\mathrm{Na}_{\mathrm{v}} 1.2$ instead of $\mathrm{Na}_{\mathrm{v}} 1.6$ (Fig. $7 B$ ), which is the same pattern observed in developing rat retina (Fig. 6). Therefore, the developmental switch from $\mathrm{Na}_{\mathrm{v}} 1.2$ to $\mathrm{Na}_{\mathrm{v}} 1.6$ at the initial segment takes place normally in the Shiverer retina. In contrast, the isoform switch fails to occur normally in the hypomyelinated Shiverer optic nerve (Boiko et al., 2001). The overall pattern suggests that absence of compact myelin and the resulting deficiencies in paranode formation (Rasband et al., 1999) disrupt 
Table 1. Percentage of total initial segments labeled by isoform-specific sodiumchannel antibodies

\begin{tabular}{lll}
\hline Age & $\begin{array}{l}\mathrm{Na}_{\mathrm{v}} 1.2-\text { positive initial segments } \\
\text { (percentage of total) }\end{array}$ & $\begin{array}{l}\mathrm{Na}_{\mathrm{v}} \text { 1.6-positive initial segments } \\
\text { (percentage of total) }\end{array}$ \\
\hline P2 & $95.7(176 / 184)$ & $2.6(7 / 274)$ \\
P9 & $99.4(172 / 173)$ & $40.9(99 / 242)$ \\
P14 & $97.3(181 / 186)$ & $80(132 / 165)$ \\
Adult & $92(92 / 100)$ & $95.3(242 / 254)$
\end{tabular}

Initial segments were defined by ankyrin-G immunostaining.

local conditions required for $\mathrm{Na}_{\mathrm{v}} 1.6$ targeting and/or stabilization in the myelinated optic nerve rather than the global expression of $\mathrm{Na}_{\mathrm{v}} 1.6$ by RGCs.
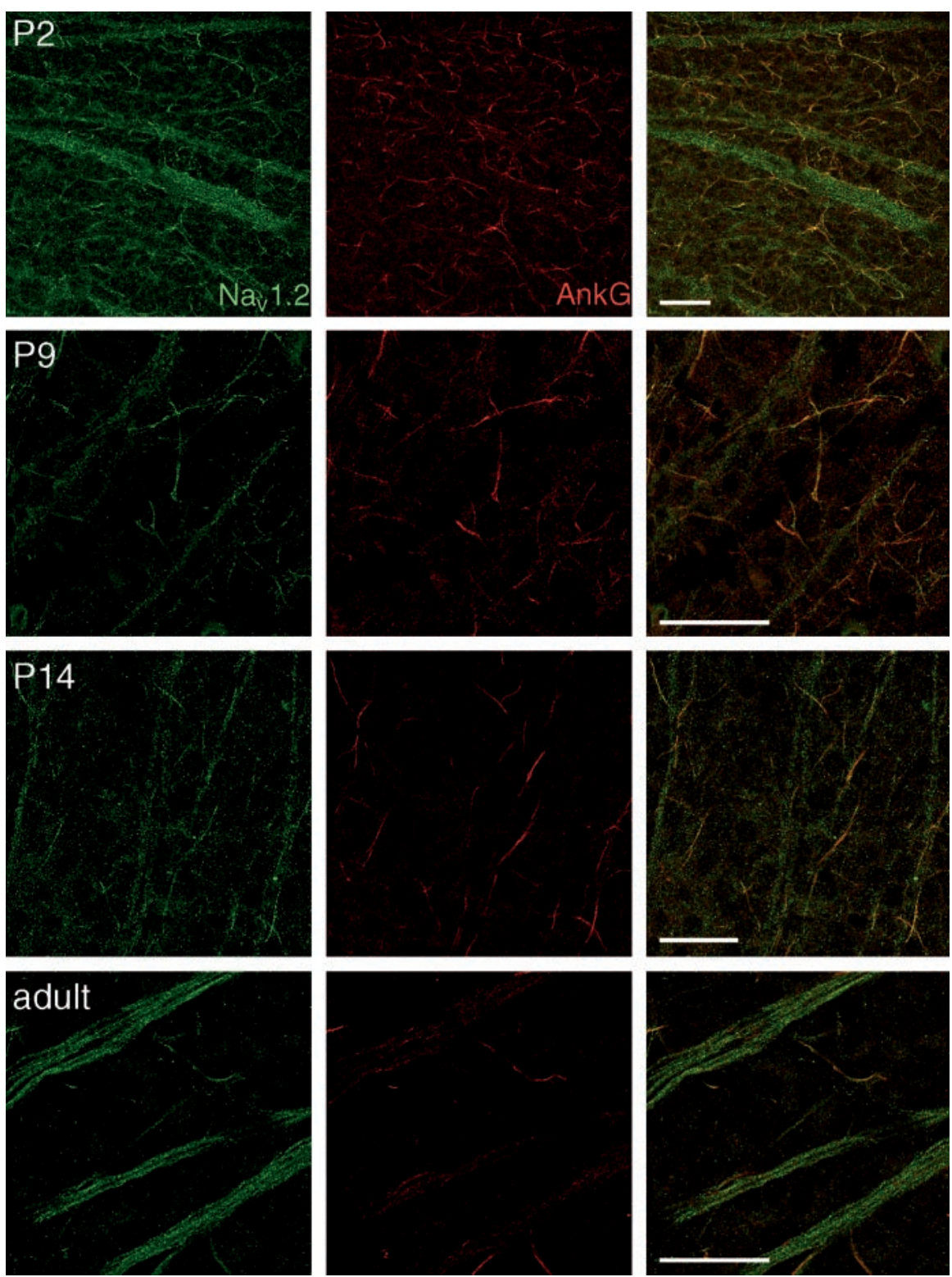

Figure 6. Early initial segments during retinal development were brightly labeled with anti- $\mathrm{Na}_{\mathrm{v}} 1$.2. The presence of $\mathrm{Na}_{\mathrm{v}} 1.2$ is maintained at RGC initial segments throughout development. Flat mounts of rat retina were immunostained for $\mathrm{Na}_{\mathrm{v}} 1.2$ and ankyrin- $\mathrm{G}(A n k G)$ at different postnatal ages. Na 1.2 staining was detected at ankyrin-G-defined initial segments at all ages, as well as throughout the unmyelinated RGC fibers. Scale bar, $40 \mu \mathrm{m}$. Images are single optical sections.

\section{Discussion}

In the unmyelinated region of $\mathrm{RGC}$ axons, $\mathrm{Na}_{\mathrm{v}} 1.6$ expression is restricted to the initial segments, where it colocalizes with ankyrin-G

Ankyrin-G is a member of membrane-associated spectrin/actininteracting ankyrin proteins and is believed to tie sodium channels to the cytoskeleton at sites of high sodium-channel density. It is found at nodes of Ranvier, axonal initial segments, and postsynaptic folds of neuromuscular junctions (for review, see Bennett and Baines, 2001). Ankyrin-G was found to be essential for proper sodiumchannel expression in the initial segments of cerebellar neurons (Zhou et al., 1998; Jenkins and Bennett, 2001). Thus expression of ankyrin-G defines specialized domains of sodium-channel clustering (Bennett and Baines, 2001). Because RGC axons consist of a relatively long unmyelinated zone proximal to the lamina cribrosa, their initial segments are far removed from the myelinated regions and therefore cannot be considered simply as first nodes. In unmyelinated RGC axons, $\mathrm{Na}_{\mathrm{v}} 1.6$ sodium-channel immunoreactivity was detected specifically at the distal portion of initial segments, where it was found to colocalize with ankyrin-G and the celladhesion molecule neurofascin. The selective localization of $\mathrm{Na}_{\mathrm{v}} 1.6$ sodium channels at the initial segment demonstrates that this part of the unmyelinated axon forms a functionally distinct subcompartment, where channels of a distinct type cluster at high density.

Wollner and Catterall (1986) reported a high density of sodium-channel immunoreactivity at sites proximal to RGC somata in immunoperoxidase-stained $10 \mu \mathrm{m}$ sections, which they interpreted to represent sodium-channel staining throughout the initial segment and axon hillock. In contrast, we found a high density of sodium channels only in the distal initial segment, with dimmer immunofluorescence in the proximal initial segment and axon hillock. This localization was confirmed in our work by immunostaining for molecular partners of sodium channels. Because it can be difficult to establish unambiguously that a particular brightly stained process is associated with a specific ganglion cell, especially in sections, the issue of the density of sodium channels in the hillock and proximal initial segment requires additional study. For example, confocal imaging of individual dye-injected ganglion cells could be used in conjunction with immunofluorescence sodium-channel staining to establish clearly the cell of origin of a particular axon. However, we point out that the localization reported here is consistent with the modeling study of Fohlmeister and Miller (1997), who found that a high density of sodium channels in the distal part of the initial segment (their "thin segment") is required to simulate RGC firing behavior. In addition, direct recordings from initial segments of neocortical pyramidal neurons demonstrated that 

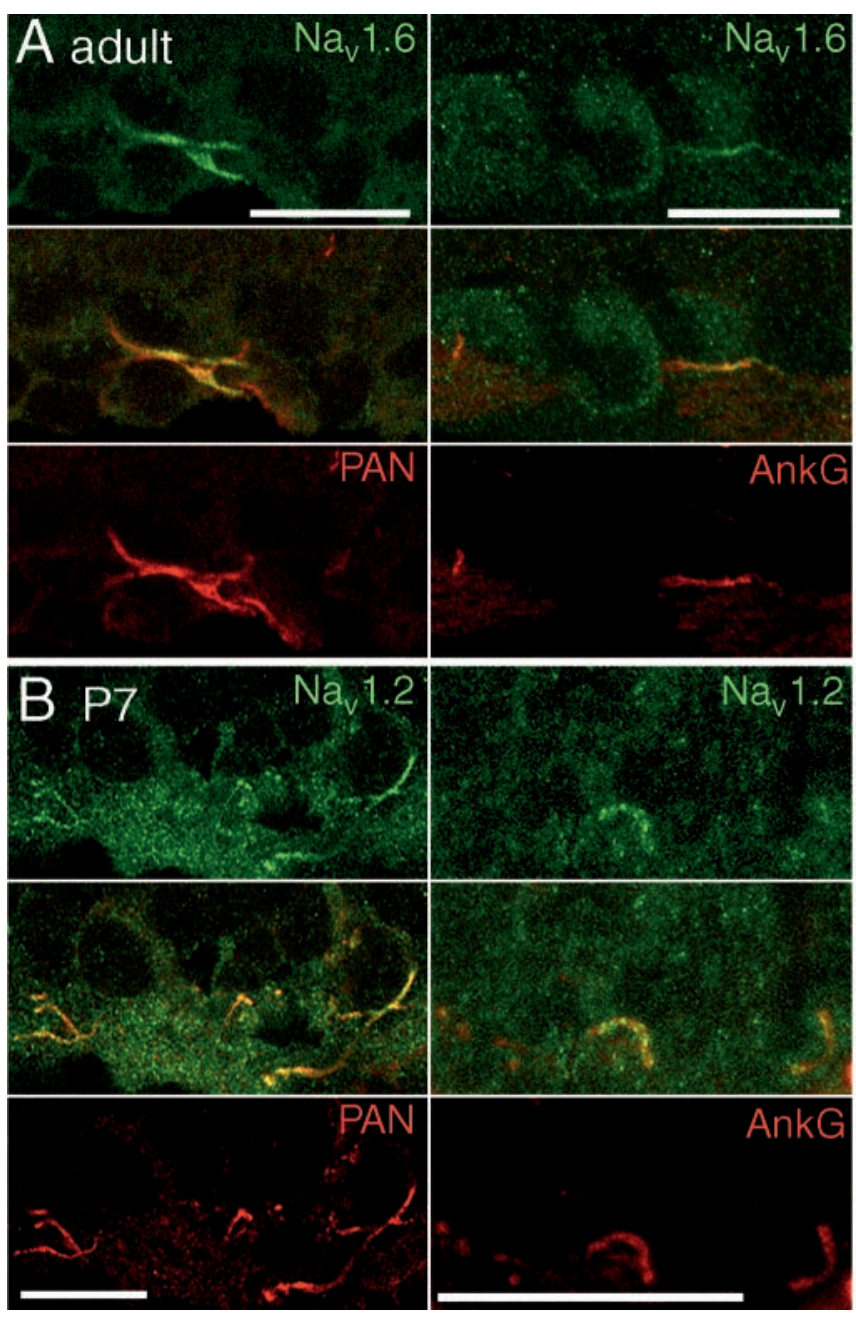

Figure 7. Hypomyelination of $\mathrm{RGC}$ axons does not disrupt $\mathrm{Na}_{\mathrm{v}} 1.6$ targeting at $\mathrm{RGC}$ initial segments in the retina of Shiverer mice. $A$, Cryosections from adult Shiverer retina were stained with anti-Na 1.6 (green) and PAN (red, left) or anti-ankyrin-G (AnkG; red, right). Images are single confocal sections (left) or projections of optical sections spanning $3 \mu \mathrm{m}$ (right). The staining pattern in adult Shiverer retina was indistinguishable from that in wild-type mice (data not shown) or rat retina (Figs. 1, 2). B, In the retina of P7 Shiverer mice, anti-Na 1.2 (green) stains all brightly PAN-labeled axonal regions (red, left), in which pronounced anti- $\mathrm{Na}_{\mathrm{v}} 1.6$ labeling was observed in the adult $(A)$. Similarly, $\mathrm{Na}_{\mathrm{v}} 1.2$ immunoreactivity ( green, right) colocalized with ankyrin-G-positive initial segments (red, right) in P7 Shiverer retina. Images on the left are of single optical sections, and images on the right are projections of sections spanning $2.5 \mu \mathrm{m}$. Scale bar, $20 \mu \mathrm{m}$.

action potentials originate at a site $\geq 30 \mu \mathrm{m}$ distal to the soma (Stuart et al., 1997), which is also consistent with sodium-channel clustering in the distal portion of the initial segment.

At mature nodes of Ranvier, $\mathrm{Na}_{\mathrm{v}} 1.2$ immunostaining is detectable at $<20 \%$ of nodes (Boiko et al., 2001), whereas we report here that $>90 \%$ of adult initial segments were positive for $\mathrm{Na}_{\mathrm{v}} 1.2$. Thus, the mechanisms responsible for selective targeting of $\mathrm{Na}_{\mathrm{v}} 1.6$ to the initial segment do not exclude $\mathrm{Na}_{\mathrm{v}} 1.2$ from this same site. Indeed, at early stages, before the appearance of $\mathrm{Na}_{\mathrm{v}} 1.6$, only $\mathrm{Na}_{\mathrm{v}} 1.2$ was observed at initial segments (Fig. 6, Table 1). Together with the universal presence of $\mathrm{Na}_{\mathrm{v}} 1.2$ at developing nodes of Ranvier reported by Boiko et al. (2001), this finding indicates that $\mathrm{Na}_{\mathrm{v}} 1.2$ channels can and do interact with anchoring mechanisms at both nodes of Ranvier and initial segments.
The rise in $\mathrm{Na}_{\mathrm{v}} 1.6$ expression at initial segments during development parallels the appearance of $\mathrm{Na}_{\mathrm{v}} 1.6$ at developing nodes of Ranvier

We found that the molecular composition of the initial segment is developmentally regulated. At P2, only 3\% of initial segments exhibited detectable $\mathrm{Na}_{\mathrm{v}} 1.6$ expression, but by $\mathrm{P} 9$ and P14, the percentage of $\mathrm{Na}_{\mathrm{v}} 1.6$-positive initial segments had risen to 40 and $80 \%$, respectively. This rise in $\mathrm{Na}_{\mathrm{v}} 1.6$ at initial segments coincides with the rapid appearance of $\mathrm{Na}_{\mathrm{v}} 1.6$ immunoreactivity at nodes of Ranvier during myelination of the optic nerve, in which the percentage of $\mathrm{Na}_{\mathrm{v}} 1$.6-positive nodes increased from $\sim 20 \%$ at P9-P10 to $>90 \%$ at P14 (Boiko et al., 2001). Myelination in the optic nerve proceeds rapidly in this same time frame (Rasband et al., 1999; Boiko et al., 2001), and expression of $\mathrm{Na}_{\mathrm{v}} 1.6$ at nodes correlated with node maturation (Boiko et al., 2001). This suggests that expression of the $\mathrm{Na}_{\mathrm{v}} 1.6$ gene might be triggered by events related to the formation of mature nodes of Ranvier, such as the completion of normal axoglial contacts in the myelinated portion of the optic nerve. However, we have now found that $\mathrm{Na}_{\mathrm{v}} 1.6$ expression at the RGC initial segment is normal in Shiverer mice (Fig. 7). This finding suggests that the aberrant expression of $\mathrm{Na}_{\mathrm{v}} 1.6$ channels in the Shiverer optic nerve may represent failure of channel targeting and stabilization, possibly related to abnormal axoglial contact (Rosenbluth, 1981; Rasband et al., 1999) and consequent incorrect localization of partner proteins necessary for nodal clustering. The expression of any such partners is presumably unaffected at the Shiverer initial segment, where $\mathrm{Na}_{\mathrm{v}} 1.6$ insertion and retention appeared normal. It is also possible that a combination of reduced gene expression and failure of targeting accounts for diminished $\mathrm{Na}_{\mathrm{v}} 1.6$ expression in the myelinated optic nerve but not at initial segments in Shiverer mice.

\section{Functional implications of $\mathrm{Na}_{\mathrm{v}} 1.6$ expression at the initial segment}

The axon initial segment is a strategic location for determining the firing characteristics of a neuron, and therefore the signal passed to subsequent stages of neural processing. Beyond the mere increase in channel density at the initial segment, the biophysical properties of the sodium channels at that location may also be an important determinant of firing characteristics (Colbert and Pan, 2002). In this light, what aspect of $\mathrm{Na}_{\mathrm{v}} 1.6$ sodium channels might account for the fact that they are specifically targeted to the initial segment, instead of the $\mathrm{Na}_{\mathrm{v}} 1.2$ channels that populate the surrounding regions of the axon? One clue comes from studies examining the firing properties of neurons in mice lacking $\mathrm{Na}_{\mathrm{v}} 1.6$ (Raman et al., 1997). Cerebellar Purkinje cells from these mice have diminished ability to fire bursts of action potentials. $\mathrm{Na}_{\mathrm{v}} 1.6$ is necessary (albeit not sufficient by itself) for resurgent sodium current, which recovers from inactivation during moderate sustained depolarization and thus promotes repetitive firing. Retinal ganglion cells are the locus for translating the graded responses to illumination found in photoreceptors and bipolar cells into a frequency code of action potentials that carry the information over a long distance along the optic nerve. We speculate, therefore, that the ability of $\mathrm{Na}_{\mathrm{v}} 1.6$ channels to support resurgent current, and thus to promote repetitive spiking, enhances the fidelity of translating graded synaptic signals into the frequency code of illumination intensity.

Another clue regarding the possible function of $\mathrm{Na}_{\mathrm{v}} 1.6$ at the RGC initial segment stems from developmental studies of firing properties of RGCs. In developing rat retina, RGCs at P7-P9 typically fired only a single action potential during prolonged 
depolarization (Wang et al., 1997). However, between P7 and P24, the fraction of cells that fire repetitively increased progressively, accompanied by a decline in the fraction of cells that fire single spikes. This change in firing properties was attributed by Wang et al. (1997) to a speeding of recovery from inactivation of voltage-sensitive sodium channels. The time course of the developmental shift in firing properties of RGCs is similar to the period when $\mathrm{Na}_{\mathrm{v}} 1.6$ sodium channels first appear at the initial segment. Thus, the developmental change in repetitive firing and in sodium-channel inactivation reported by Wang et al. (1997) may be attributable to the developmental appearance of $\mathrm{Na}_{\mathrm{v}} 1.6$ sodium channels at the initial segment reported here.

\section{References}

Bennett V, Baines AJ (2001) Spectrin and ankyrin-based pathways: metazoan inventions for integrating cells into tissues. Physiol Rev 81:1353-1392.

Berghs S, Aggujaro D, Dirkx Jr R, Maksimova E, Stabach P, Hermel JM, Zhang JP, Philbrick W, Slepnev V, Ort T, Solimena M (2000) $\beta$ IV Spectrin, a new spectrin localized at axon initial segments and nodes of Ranvier in the central and peripheral nervous system. J Cell Biol 151:985-1002.

Boiko T, Rasband MN, Levinson SR, Caldwell JH, Mandel G, Trimmer JS, Matthews G (2001) Compact myelin dictates the differential targeting of two sodium channel isoforms in the same axon. Neuron 30:91-104.

Caldwell JH, Schaller KL, Lasher RS, Peles E, Levinson SR (2000) Sodium channel $\mathrm{Na}_{\mathrm{v}} 1.6$ is localized at nodes of Ranvier, dendrites, and synapses. Proc Natl Acad Sci USA 97:5616-5620.

Carras PL, Coleman PA, Miller RF (1992) Site of action potential initiation in amphibian retinal ganglion cells. J Neurophysiol 67:292-304.

Catterall WA (1981) Localization of sodium channels in cultured neural cells. J Neurosci 1:777-783.

Colbert CM, Pan E (2002) Ion channel properties underlying axonal action potential initiation in pyramidal neurons. Nat Neurosci 5:533-538.

Coombs JS, Curtis DR, Eccles JC (1957) The generation of impulses in motoneurones. J Physiol (Lond) 139:232-249.

Crespo D, O'Leary DD, Cowan WM (1985) Changes in the numbers of optic nerve fibers during late prenatal and postnatal development in the albino rat. Brain Res 351:129-134.

Davis JQ, Lambert S, Bennett V (1996) Molecular composition of the node of Ranvier: identification of ankyrin-binding cell adhesion molecules neurofascin (mucin +/third FNIII domain -) and NrCAM at nodal axon segments. J Cell Biol 135:1355-1367.

Dugandzija-Novakovic S, Koszowski AG, Levinson SR, Shrager P (1995) Clustering of Na channels and node of Ranvier formation in remyelinating axons. J Neurosci 15:492-502.

Fohlmeister JF, Miller RF (1997) Mechanisms by which cell geometry controls repetitive impulse firing in retinal ganglion cells. J Neurophysiol 78:1948-1964.

Gong B, Rhodes KJ, Bekele-Arcuri Z, Trimmer JS (1999) Type I and type II $\mathrm{Na}^{+}$channel alpha-subunit polypeptides exhibit distinct spatial and temporal patterning, and association with auxiliary subunits in rat brain. J Comp Neurol 412:342-352.
Jenkins SM, Bennett V (2001) Ankyrin-G coordinates assembly of the spectrin-based membrane skeleton, voltage-gated sodium channels, and L1 CAMs at Purkinje neuron initial segments. J Cell Biol 155:739-746.

Komada M, Soriano P (2002) $\beta$ IV-spectrin regulates sodium channel clustering through ankyrin-G at axon initial segments and nodes of Ranvier. J Cell Biol 156:337-348.

Kordeli E, Lambert S, Bennett V (1995) Ankyrin $_{\mathrm{G}}$. A new ankyrin gene with neural-specific isoforms localized at the axonal initial segment and node of Ranvier. J Biol Chem 270:2352-2359.

Krzemien DM, Schaller KL, Levinson SR, Caldwell JH (2000) Immunolocalization of sodium channel isoform $\mathrm{NaCh} 6$ in the nervous system. J Comp Neurol 420:70-83.

Lambert S, Davis JQ, Bennett V (1997) Morphogenesis of the node of Ranvier: coclusters of ankyrin and ankyrin-binding integral proteins define early developmental intermediates. J Neurosci 17:7025-7036.

Maslim J, Webster M, Stone J (1986) Stages in the structural differentiation of retinal ganglion cells. J Comp Neurol 254:382-402.

Palay SL, Sotelo C, Peters A, Orkand PM (1968) The axon hillock and the initial segment. J Cell Biol 38:193-201.

Peles E, Salzer JL (2000) Molecular domains of myelinated axons. Curr Opin Neurobiol 10:558-565.

Perry VH, Henderson Z, Linden R (1983) Postnatal changes in retinal ganglion cell and optic axon populations in the pigmented rat. J Comp Neurol 219:356-368.

Raman IM, Sprunger LK, Meisler MH, Bean BP (1997) Altered subthreshold sodium currents and disrupted firing patterns in Purkinje neurons of Scn8a mutant mice. Neuron 19:881-891.

Rasband MN, Peles E, Trimmer JS, Levinson SR, Lux SE, Shrager P (1999) Dependence of nodal sodium channel clustering on paranodal axoglial contact in the developing CNS. J Neurosci 19:7516-7528.

Rosenbluth J (1981) Axoglial junctions in the mouse mutant Shiverer. Brain Res 208:283-297.

Stuart G, Schiller J, Sakmann B (1997) Action potential initiation and propagation in rat neocortical pyramidal neurons. J Physiol (Lond) 505:617-632.

Voigt T, Wässle H (1987) Dopaminergic innervation of AII amacrine cells in mammalian retina. J Neurosci 7:4115-4128.

Wang GY, Ratto G-M, Bisti S, Chalupa LM (1997) Functional development of intrinsic properties in ganglion cells of the mammalian retina. J Neurophysiol 78:2895-2903.

Westenbroek RE, Merrick DK, Catterall WA (1989) Differential subcellular localization of the RI and RII $\mathrm{Na}^{+}$channel subtypes in central neurons. Neuron 3:695-704.

Wollner DA, Catterall WA (1986) Localization of sodium channels in axon hillocks and initial segments of retinal ganglion cells. Proc Natl Acad Sci USA 83:8424-8428.

Wong RO (1999) Retinal waves and visual system development. Annu Rev Neurosci 22:29-47.

Zhou D, Lambert S, Malen PL, Carpenter S, Boland LM, Bennett V (1998) Ankyrin $_{\mathrm{G}}$ is required for clustering of voltage-gated $\mathrm{Na}$ channels at axon initial segments and for normal action potential firing. J Cell Biol 143: 1295-1304. 